\title{
Editorial, IAPC-6 Meeting
}

\author{
Kin Tam ${ }^{\prime} \cdot$ Tonglei Li ${ }^{2} \cdot$ Zoran Mandić ${ }^{3}$ (D)
}

Received: 24 September 2018 / Accepted: 24 September 2018 / Published online: 18 October 2018

(C) Springer Science+Business Media, LLC, part of Springer Nature 2018

It is with our great pleasure to announce this topical issue of Pharmaceutical Research devoted to the IAPC-6 meeting held in Zagreb, Croatia, September $4-7,2017$. The meeting was organized by the International Association of Physical Chemists, nonprofit organization, with the goal to establish contacts, interactions among scientists of different profiles and to strengthen the cooperation between researchers from academia and industry. These goals go fully along with the missions of the Society which include global innovation and partnership in order to advance science and spread knowledge.

The IAPC meetings started as a series of the biennial conferences on physico-chemical methods in drug discovery and development. The first conference took place in Rovinj, Croatia, 2009, but soon it acquired a widespread interest among pharmaceutical science

Zoran Mandić

zmandic@fkit.hr

Kin Tam

kintam@umac.mo

Tonglei Li

tonglei@purdue.edu

Faculty of Health Sciences, University of Macau, Macau, China

2 Department of Industrial \& Physical Pharmacy, Purdue University, West Lafayette, Indiana 47907, USA

3 Faculty of Chemical Engineering and Technology, University of Zagreb, HR- 10000 Zagreb, Croatia community usually gathering more than 100 scientists from different parts of the world. However, its global importance the conference gained after ever increasing need to widen its geographical footprint. The scientific committee decided to switch the schedule of the Meetings from biennial to annual taking place in the alternating Eastern Asia/European locations. As a result IAPG-5 conference in Zhuhai, China, August 2016, IAPG-6 conference in Zagreb, Croatia, September 2017 (Fig. 1) and IAPG-7 conference, Osaka, Japan were organized.

IAPC-6 conference in Zagreb achieved a great success both from the scientific and social points of view. The scientific program was well balanced consisting of six sessions: Drug Development, Solid State, Pharmaceutical Cocrystals, PhysChem and Permeability, ADMET and DMPK and Drug Discovery. The conference attended about 150 participants from more than 30 countries. Special evening session, "Pharmaceutical Cocrystals Physicochemical Properties and Formulations", was organized and moderated by Alex Avdeef. The session highlighted issues related to the measurement of physicochemical properties, particularly dissolution and solubility as a function of $\mathrm{pH}$, in support of formulation development of oral drug products with improved bioavailability.

In this special issue of Pharmaceutical Research a collection of five papers were published, four of which were in the areas of preformulation study, including formulation design (Parikh \& Serajuddin, Cetina-Cizmek et al...), characterization (Grassi et al) and modelling (Avdeef). The last paper reported a computational approach to model PK and biological effects of steroids in humans. 


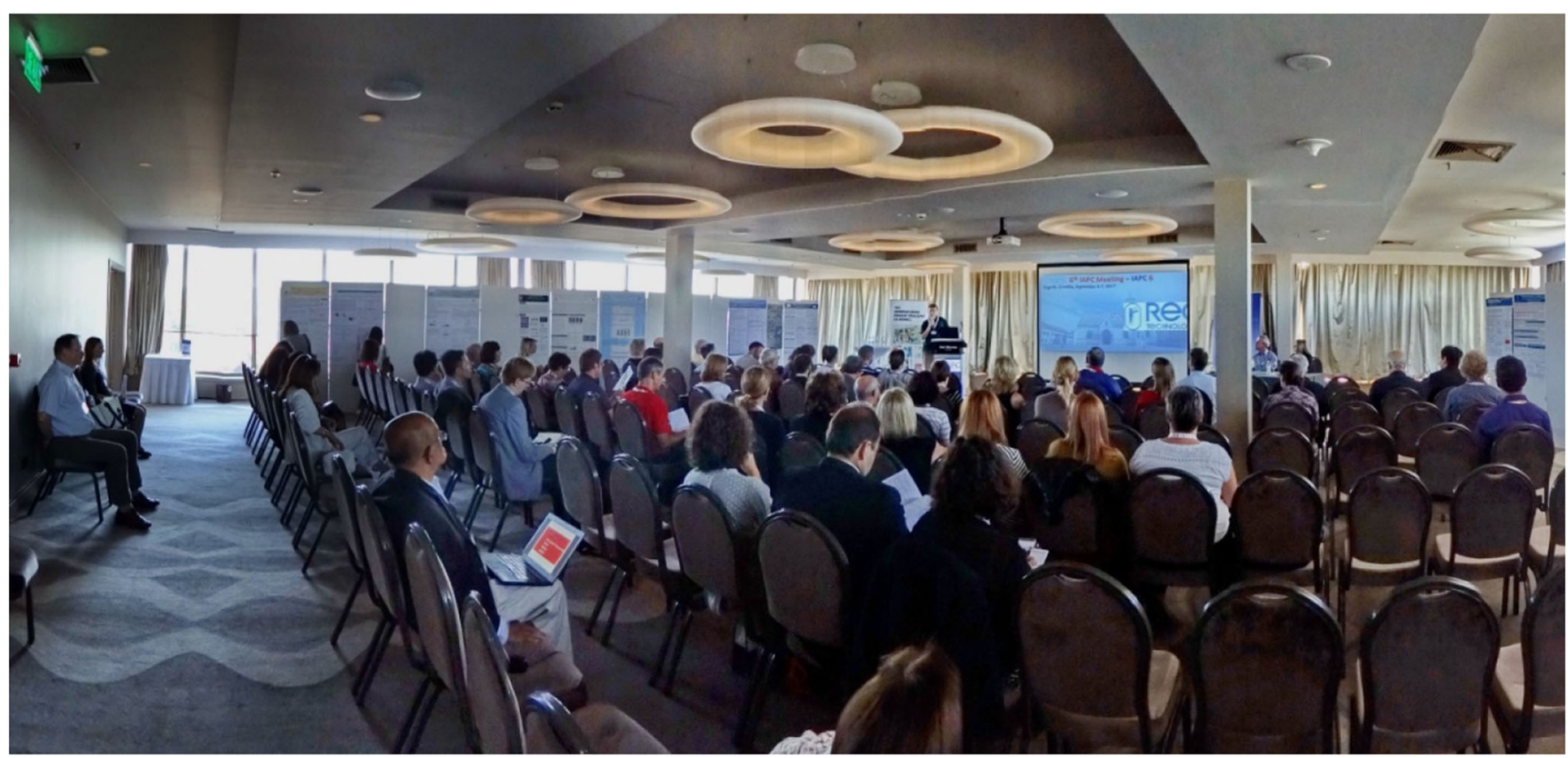

Fig. I Opening session of IAPC-6 meeting.

Three-day intensive course " 3 rd International Summer School on Drug Development" accompanied the conference as a pre-event which was organized in the facilities of PLIVA

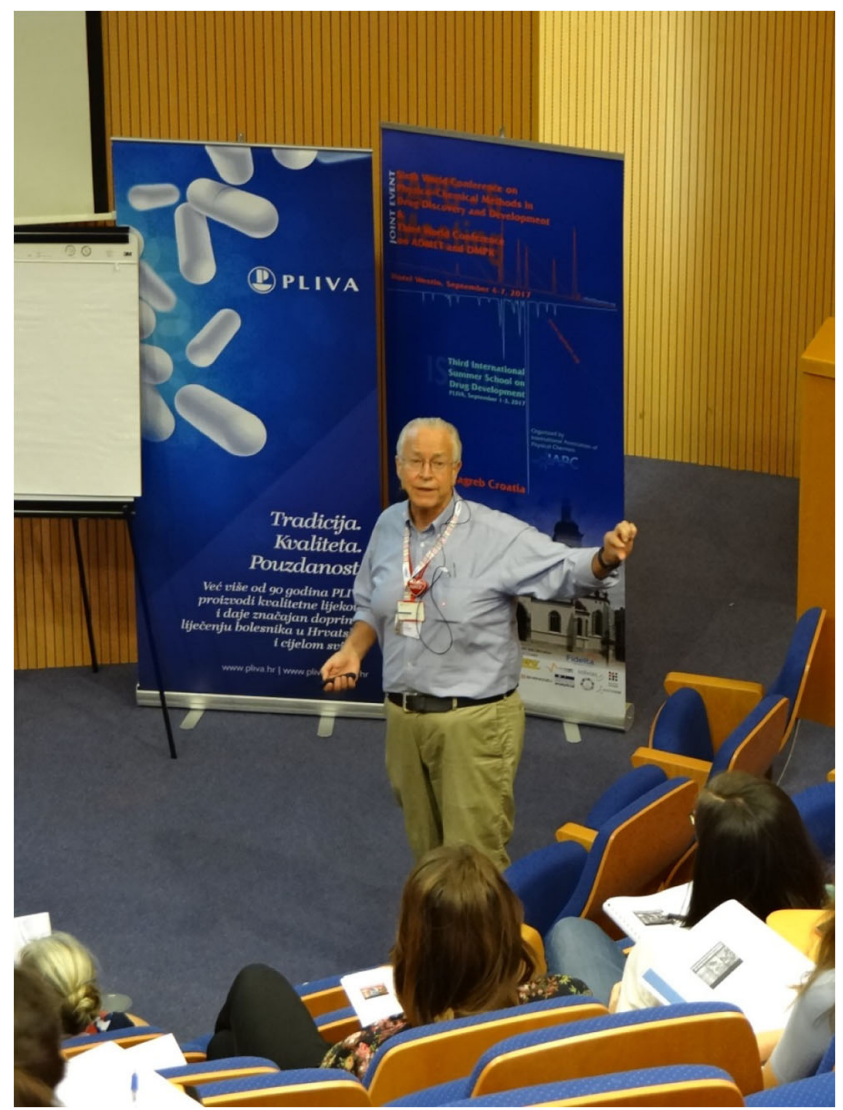

Fig. 2 Alex Avdeef giving a lecture at the 3rd international summer school on drug development. d.o.o., Croatian pharmaceutical company. The aim of the course was to provide relaxed but stimulating environment for students and other participants in order to broaden their knowledge and advance in the career (Fig. 2). 